\title{
Interleukin 18 Inhibits Osteoclast Formation via T Cell Production of Granulocyte Macrophage Colony-stimulating Factor
}

\author{
Nicole J. Horwood, ${ }^{\star}$ Nobuyuki Udagawa, ${ }^{\ddagger}$ Jan Elliott, ${ }^{\star}$ Dianne Grail, ${ }^{\S}$ Haruki Okamura, Masashi Kurimoto, \\ T. John Martin, ${ }^{*}$ and Matthew T. Gillespie* \\ *St. Vincent's Institute of Medical Research and The University of Melbourne, Department of Medicine, St. Vincent's Hospital, Fitzroy, \\ Victoria 3065, Australia; ${ }^{\ddagger}$ Department of Biochemistry, School of Dentistry, Showa University, Tokyo 142, Japan; ${ }^{\circledR}$ Ludwig Institute for \\ Cancer Research, Royal Parade, Parkville, Victoria 3052, Australia; "Department of Immunology and Medical Zoology, Hyogo College of \\ Medicine, Nishinomiya 663, Japan; and ${ }^{\mathbb{I}}$ Fujisaki Institute, Hayashibara Biochemical Laboratories, Inc., Okayama 702, Japan
}

\begin{abstract}
IL-18 inhibits osteoclast (OCL) formation in vitro independent of IFN- $\gamma$ production, and this was abolished by the addition of neutralizing antibodies to GM-CSF. We now establish that IL-18 was unable to inhibit OCL formation in cocultures using GM-CSF-deficient mice (GM-CSF -/-). Reciprocal cocultures using either wild-type osteoblasts with GM-CSF $-I-$ spleen cells or GM-CSF $-I-$ osteoblasts with wild-type spleen cells were examined. Wild-type spleen cells were required to elicit a response to IL-18 indicating that cells of splenic origin were the IL-18 target. As T cells comprise a large proportion of the spleen cell population, the role of $\mathrm{T}$ cells in osteoclastogenesis was examined. Total $T$ cells were removed and repleted in various combinations. Addition of wild-type T cells to a GM-CSF -Icoculture restored IL-18 inhibition of osteoclastogenesis. Major subsets of $\mathrm{T}$ cells, $\mathrm{CD}^{+}$and $\mathrm{CD8}^{+}$, were also individually depleted. Addition of either $\mathrm{CD}^{+}$or $\mathrm{CD}^{+}$wildtype $T$ cells restored IL-18 action in a GM-CSF $-/-$ background, while IL-18 was ineffective when either $\mathrm{CD}^{+}$or $\mathrm{CD8}^{+}$GM-CSF $-I-\mathrm{T}$ cells were added to a wild-type coculture. These results highlight the involvement of $T$ cells in IL-18-induced OCL inhibition and provide evidence for a new OCL inhibitory pathway whereby IL-18 inhibits OCL formation due to action upon $\mathrm{T}$ cells promoting the release of GM-CSF, which in turn acts upon OCL precursors. $(J$. Clin. Invest. 1998. 101:595-603.) Key words: bone development • cytokines - osteoblasts • spleen • T lymphocyte subsets
\end{abstract}

\section{Introduction}

Bone remodeling involves the highly regulated coupling of resorption and formation. Osteoclasts (OCL) ${ }^{1}$ are the principle bone resorbing cells, whereas osteoblastic stromal cells are responsible for matrix deposition. A multitude of local and sys-

Address correspondence to Dr. Matthew T. Gillespie, St. Vincent's Institute of Medical Research, 41 Victoria Parade, Fitzroy 3065, Victoria, Australia. Phone: 61-3-9288-2480; FAX: 61-3-9416-2676; E-mail: m.gillespie@medicine.unimelb.edu.au

Received for publication 29 July 1997 and accepted in revised form 8 December 1997.

J. Clin. Invest.

(C) The American Society for Clinical Investigation, Inc. 0021-9738/98/02/0595/09 \$2.00

Volume 101, Number 3, February 1998, 595-603

http://www.jci.org temic factors act directly or indirectly via other cell types to influence OCL differentiation and activation (1). The most important cell types influencing OCL formation are those of the osteoblast lineage (2) which promote this process by a contact-dependent mechanism (3). The precise role of other cells, such as T lymphocytes, in bone homeostasis is yet to be fully elucidated. Postmenopausal osteoporosis has been linked with variations in the ratio of $\mathrm{T}$ lymphocyte markers, $\mathrm{CD} 4^{+} / \mathrm{CD} 8^{+}$ (4). However, subsequent studies have failed to show a significant difference in $\mathrm{T}$ lymphocyte ratios between untreated osteoporotic postmenopausal women and nonosteoporotic postmenopausal women $(5,6)$. The administration of cyclosporin A, a T lymphocyte-mediated immunosuppressant, leads to high bone turnover with resorption exceeding formation, resulting in severe osteopenia in rat models (7). Furthermore, it has been postulated that $\mathrm{CD}^{+} \mathrm{T}$ cells may be involved in osteoclastogenesis since depletion of this cell type results in increased OCL formation (8).

IL-18 was isolated from activated murine macrophages and Kupffer cells in response to toxic shock and shares functional similarities with IL-12 (9). Human IL-18 acts to enhance production of IFN- $\gamma$ and GM-CSF in peripheral blood mononuclear cells (10), whereas production of T helper type 1 cytokines, IL-2, GM-CSF, and IFN- $\gamma$, are enhanced by IL-18 stimulation of human T cells (11). Interestingly, B cells stimulated by IL-18 also produce significant quantities of IFN- $\gamma$ (12). Recently, we have shown that IL-18 was produced by osteoblastic stromal cells and inhibits OCL formation in a coculture system of mouse hematopoietic and primary osteoblastic stromal cells (13). This action appeared to be mediated via GM-CSF production, not IFN- $\gamma$, since neutralizing antibodies to GM-CSF were able to rescue IL-18-induced inhibition of osteoclastogenesis.

This study has been designed to investigate the role of GMCSF in determining the response to IL-18 stimulation in cocultures and the significance of T cells in OCL development.

\section{Methods}

Animals, cell lines, and drugs. Newborn (0-1-d-old) C57/BL6J mice (wild-type, WT) were purchased from Monash University Animal Services Centre (Clayton, Australia). GM-CSF-deficient mice were as published (GM-CSF -/-) (14) and GM-CSF/IL-3/IL-5 $\beta$ chain receptor-deficient mice (GM-CSF R -/-) were provided by Glenn

1. Abbreviations used in this paper: GM-CSF -/-, GM-CSF knockout; GM-CSF R -/-, GM-CSF $\beta$ chain receptor knockout; M-CSF, macrophage colony-stimulating factor; OCL, osteoclast-like multinucleated cells; TRAP, tartrate-resistant acid phosphatase; WT, wildtype. 
Begley (Walter \& Eliza Hall Institute of Medical Research, Australia) (15). $1 \alpha, 25(\mathrm{OH})_{2} \mathrm{D}_{3}$ was purchased from Wako Pure Chemical Co. (Osaka, Japan) and $\mathrm{PGE}_{2}$ was obtained from Sigma Chemical Co. (St. Louis, MO). Recombinant mouse IL-18 and rabbit polyclonal antibodies to mouse IL-18 were prepared as described (9). GM-CSF and anti-mouse GM-CSF polyclonal antibody ( $\alpha$ GM-CSF) were purchased from R\&D Systems (Minneapolis, MN). Bacterial collagenase was obtained from Worthington Biochemical Co. (Freefold, Australia). Other chemicals and reagents were of analytical grade.

Coculture system. Osteoblastic cells were prepared from the calvaria of newborn mice (WT, GM-CSF -/-, or GM-CSF R -/-) by sequential digestion with $0.1 \%$ collagenase (Worthington Biochemical Co.) and $0.2 \%$ dispase (Godo Shusei, Tokyo, Japan). Spleen cells were also obtained from each type of newborn mice by disaggregation through a wire sieve (3). Osteoblastic cells were cocultured with spleen cells as described previously $(3,16)$. The expression of calcitonin receptors was also assessed by autoradiography using $\left[{ }^{125} \mathrm{I}\right]-$ salmon calcitonin as described (3) and the OCL were tested for the ability to resorb bone (17).

Murine GM-CSF ELISA. A murine GM-CSF ELISA kit was purchased from Endogen Inc. (Cambridge, MA) and used according to the manufacturer's instructions. Supernatants from the cocultures were collected at two time points, days 3 and 7 , and stored at $-70^{\circ} \mathrm{C}$ immediately. Standards $(250-10 \mathrm{pg} / \mathrm{ml})$ were serially diluted in $\alpha$-MEM. Coculture supernatants were not diluted before assay.

Methylcellulose cultures. Bone marrow mononuclear cells were obtained from the tibiae of 7-9-wk-old male C57/BL6J mice and resuspended at a concentration of $10^{5} / \mathrm{ml}$ in $\alpha$-MEM containing $0.88 \%$ methylcellulose, $100 \mu \mathrm{M} \beta$-mercaptoethanol, and 10\% FCS. Marrow cells $\left(2 \times 10^{5} / \mathrm{dish}\right)$ were cultured in $35-\mathrm{mm}$ plastic petri dishes in the presence of $50 \mathrm{ng} / \mathrm{ml}$ of recombinant human macrophage colonystimulating factor (M-CSF; kindly provided by Morinaga Milk Co., Kanagawa, Japan). After $6 \mathrm{~d}$ of culture, the petri dishes were thoroughly washed with $\alpha$-MEM to recover all the cells grown in the methylcellulose. These cells were subsequently washed three times in $\alpha$-MEM before resuspending in $\alpha$-MEM $+10 \%$ FCS for coculture with osteoblastic cells. According to the morphology of the cells and staining with F4/80, the colonies induced by M-CSF were predominantly macrophages $(>95 \%)$, in agreement with previous studies (18). A T cell-enriched fraction of mouse spleen cells was prepared (high capacity mouse $\mathrm{T}$ cell recovery column kit; Cedarlane, Ontario, Canada) according to the manufacturer's instructions.

$T$ cell depletion/repletion. Total $\mathrm{T}$ cells were removed from spleen cell preparations using mouse pan T (Thy 1.2) Dynabeads (Dynal, Oslo, Norway) for the positive isolation or depletion of all T cell subsets. Before incubation, the Dynabeads were washed twice in $\alpha$-MEM. After disaggregation, spleen cells were resuspended at a concentration of $5 \times 10^{6}$ cells $/ \mathrm{ml}$ and mixed with Thy 1.2 precoated Dynabeads for $1 \mathrm{~h}$ at $4^{\circ} \mathrm{C}$ on a rotating wheel. T cells were considered to comprise $30-40 \%$ of the spleen cell population $\left(\sim 2 \times 10^{6}\right.$ cells $\left./ \mathrm{ml}\right)$ and the Dynabeads were added in a 10 -fold excess $\left(\sim 2 \times 10^{7}\right.$ beads $\left./ \mathrm{ml}\right)$. Subsets of $\mathrm{T}$ cells, $\mathrm{CD} 4^{+}$and $\mathrm{CD} 8^{+}$, were also separated from the spleen cells using Dynabeads mouse CD4 (L3T4) and Dynabeads mouse CD8 (Lyt2), respectively, with $>90 \%$ efficiency as determined by FACS $^{\circledR}$ analysis. Each of the T cell subpopulations were assumed to account for $50 \%$ of the total $\mathrm{T}$ cell population (or $15-20 \%$ of the
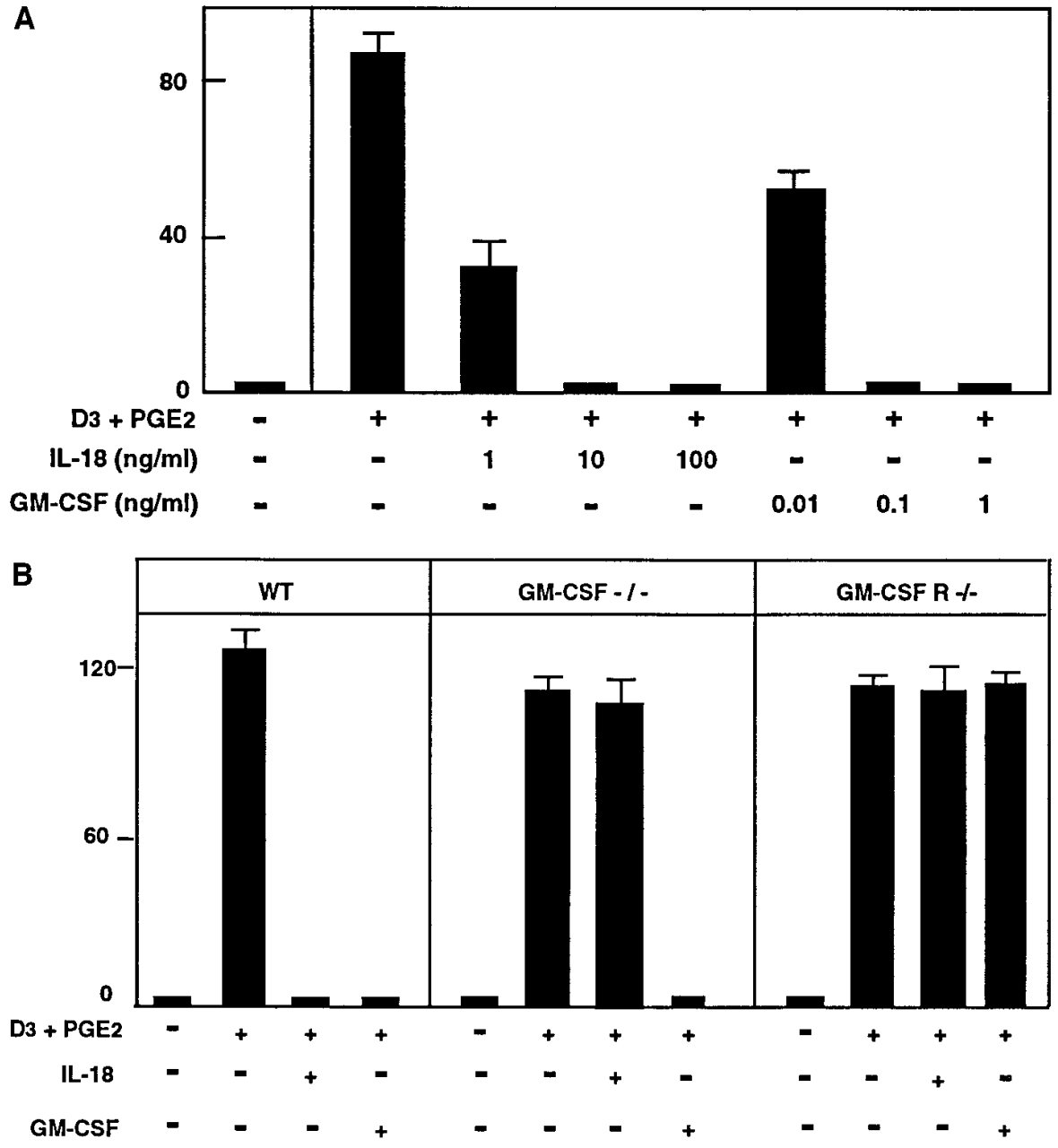

Figure 1. (A) OCL formation in cocultures of mouse spleen cells and osteoblastic cells with $1 \alpha, 25(\mathrm{OH})_{2} \mathrm{D}_{3}\left(10^{-8} \mathrm{M}\right)$ and $\mathrm{PGE}_{2}$ $\left(10^{-7} \mathrm{M}\right)$ in the presence of increasing concentrations of IL-18 or GM-CSF. For negative and positive controls, cocultures were performed in the absence and presence of $1 \alpha, 25(\mathrm{OH})_{2} \mathrm{D}_{3}$ and $\mathrm{PGE}_{2}$, respectively. After culture for $7 \mathrm{~d}$, tartrate-resistant acid phosphatase (TRAP)-positive OCLs were counted. Each coculture was repeated five times in quadruplicate wells and expressed as the means \pm SEM. ( $B)$ OCL formation in cocultures of spleen cells and osteoblastic cells derived from C57/BL6J, GM-CSF $-/-$, and GM-CSF R -/- mice, respectively. Cocultures were performed in the presence of $1 \alpha, 25(\mathrm{OH})_{2} \mathrm{D}_{3}$ and $\mathrm{PGE}_{2}$ and treated with IL-18 or GM-CSF. For negative and positive controls, cocultures were performed in the absence and presence of $1 \alpha, 25(\mathrm{OH})_{2} \mathrm{D}_{3}$ and $\mathrm{PGE}_{2}$, respectively. After culture for $7 \mathrm{~d}$, TRAP-positive OCLs were counted. Each coculture was repeated four times in quadruplicate wells and expressed as the means \pm SEM. 
spleen cell population). T cells were immunomagnetically separated from the remaining spleen cells using a magnetic particle concentrator (Dynal) and rinsed three times in $\alpha$-MEM to remove contaminating spleen cells. The final T cell/Dynabead mix was resuspended in $\alpha$-MEM for addition to the cocultures. Cocultures were established using various combinations of primary osteoblasts, T cell-depleted spleen cells, and $T$ cells attached to the Dynabeads in the presence of test chemicals as described above.

\section{Results}

OCL formation in cocultures from knockout and WT mice. We have demonstrated previously that both IL-18 and GMCSF are potent inhibitors of OCL formation in the mouse coculture system (13). Both IL-18 and GM-CSF dose-dependently inhibit OCL formation with maximally effective concentrations of 10 and $0.1 \mathrm{ng} / \mathrm{ml}$, respectively (Fig. $1 A$ ). These maximal doses were used in subsequent experiments unless otherwise stated. Using neutralizing antibodies to GM-CSF, we were able to rescue the IL-18 inhibition of OCL formation (13), indicating that GM-CSF was a central component in the action of IL-18 on OCL formation. To define the mechanism of IL-18 and the cells responsible for eliciting IL-18 actions, we used GM-CSF - /- and GM-CSF R -/- mice. Cocultures established using primary osteoblasts and spleen cells from GM$\mathrm{CSF}-/-$ newborn mice, in the presence of $1 \alpha, 25(\mathrm{OH})_{2} \mathrm{D}_{3}$ and $\mathrm{PGE}_{2}$, formed OCL in equivalent numbers to the WT cocultures (Fig. 1 B). However, in cocultures with GM-CSF -/- osteoblasts and spleen cells, IL-18 was no longer able to inhibit OCL formation (Fig. $1 \mathrm{~B}$ ), even at concentrations as high as $100 \mathrm{ng} / \mathrm{ml}$ (data not shown). Conversely, exogenous GM-CSF was able to completely inhibit OCL formation at a concentration of $0.1 \mathrm{ng} / \mathrm{ml}$ as seen in the WT cocultures (Fig. $1 B$ ). Interestingly, IFN- $\gamma(50 \mathrm{U} / \mathrm{ml})$ was also able to inhibit OCL formation in the GM-CSF $-/$ - cocultures, in agreement with our earlier findings that IL-18 acts independently of IFN-y (data not shown). Cocultures with the primary osteoblasts and spleen cells from the GM-CSF R -/- newborns were, like the other coculture regimes, able to form OCL in the presence of $1 \alpha, 25(\mathrm{OH})_{2} \mathrm{D}_{3}$ and $\mathrm{PGE}_{2}$. The addition of either IL-18 $(10 \mathrm{ng} /$ $\mathrm{ml})$ or GM-CSF $(0.1 \mathrm{ng} / \mathrm{ml})$ showed no effect on OCL formation, presumably due to the lack of a functional high-affinity GM-CSF receptor (Fig. $1 B$ ). These results demonstrated conclusively that IL-18 inhibited OCL formation via the production of GM-CSF.

IL-18 target cells. To address the potential cellular target(s) of IL-18 within the coculture system, either GM-CSF -/or GM-CSF R -/- mice were used in conjunction with WT mice. Reciprocal cocultures were established using either WT osteoblasts with spleen cells from deficient mice or osteoblasts from deficient mice with WT spleen cells. Each of the four coculture combinations formed OCL in the presence of $1 \alpha, 25(\mathrm{OH})_{2} \mathrm{D}_{3}$ and $\mathrm{PGE}_{2}$ (Fig. 2, $A$ and $B$ ). IL-18 inhibited OCL formation in the presence of WT spleen cells and osteoblasts from either GM-CSF -/- or GM-CSF R -/- mice, yet failed to show any inhibitory effect on OCL formation with spleen cells from either GM-CSF -/- or GM-CSF R -/- mice and WT osteoblasts (Fig. 2, $A$ and $B$ ). Whereas the addition of GM-CSF $(0.1 \mathrm{ng} / \mathrm{ml})$ completely inhibited OCL formation in cocultures using either WT spleen or GM-CSF -/- spleen (Fig. $2 A$ ), this agent was unable to inhibit OCL formation when GM-CSF R - /- hematopoietic cells were used as a source of OCL precursors (Fig. 2 B). In the absence of GMCSF production or a functional receptor for GM-CSF in cells of splenic origin, IL-18 was unable to inhibit OCL formation, thus highlighting the spleen cell population as the target of IL-18 action.

GM-CSF production in coculture. To confirm that IL-18 inhibited OCL formation in vitro by the production of GMCSF, a mouse GM-CSF ELISA was used to determine the concentration of endogenous GM-CSF secreted into the culture media. Media from each of the coculture wells were collected at days 3 and 7. In cocultures of GM-CSF -/- osteoblastic cells and WT spleen, IL-18 induced GM-CSF production to a
A

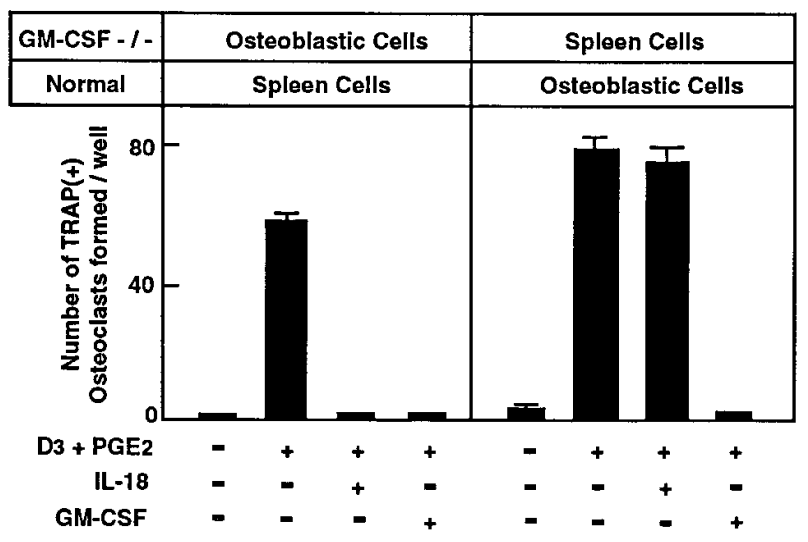

B

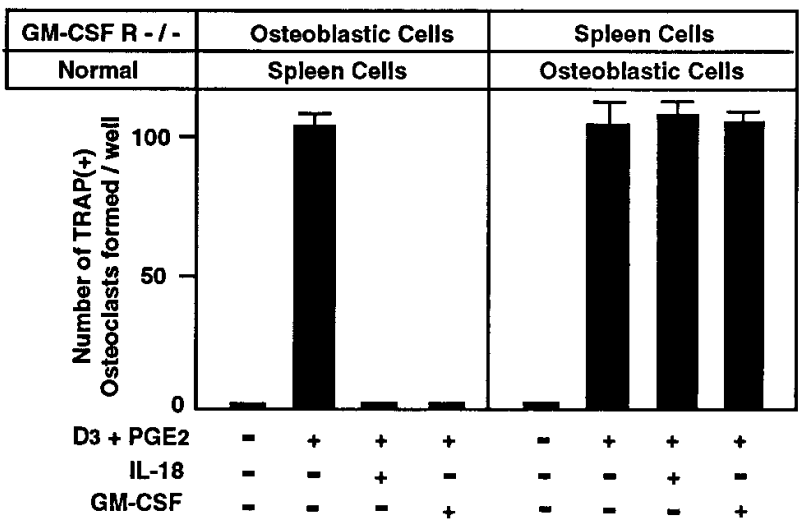

Figure 2. (A) OCL formation in reciprocal cocultures of GM-CSF $-/-$ osteoblastic cells with WT spleen or WT osteoblastic cells with GM-CSF $-/-$ spleen. Cocultures were performed in the presence of $1 \alpha, 25(\mathrm{OH})_{2} \mathrm{D}_{3}$ and $\mathrm{PGE}_{2}$ and treated with IL-18 $(10 \mathrm{ng} / \mathrm{ml}) \mathrm{or} \mathrm{GM}-\mathrm{CSF}(0.1 \mathrm{ng} / \mathrm{ml})$. For negative and positive controls, cocultures were performed in the absence and presence of $1 \alpha, 25(\mathrm{OH})_{2} \mathrm{D}_{3}$ and $\mathrm{PGE}_{2}$, respectively. After culture for $7 \mathrm{~d}$, TRAP-positive OCLs were counted. Each coculture was repeated four times in quadruplicate wells and expressed as the means \pm SEM. (B) OCL formation in reciprocal cocultures of GM-CSF R -/- osteoblastic cells with WT spleen or WT osteoblastic cells with GM-CSF R $-1-$ spleen. Cocultures were performed in the presence of $1 \alpha, 25(\mathrm{OH})_{2} \mathrm{D}_{3}$ and $\mathrm{PGE}_{2}$ and treated with IL-18 or GM-CSF. For negative and positive controls, cocultures were performed in the absence and presence of $1 \alpha, 25(\mathrm{OH})_{2} \mathrm{D}_{3}$ and $\mathrm{PGE}_{2}$, respectively. After culture for $7 \mathrm{~d}$, TRAP-positive OCLs were counted. Each coculture was repeated three times in quadruplicate wells and expressed as the means \pm SEM. 


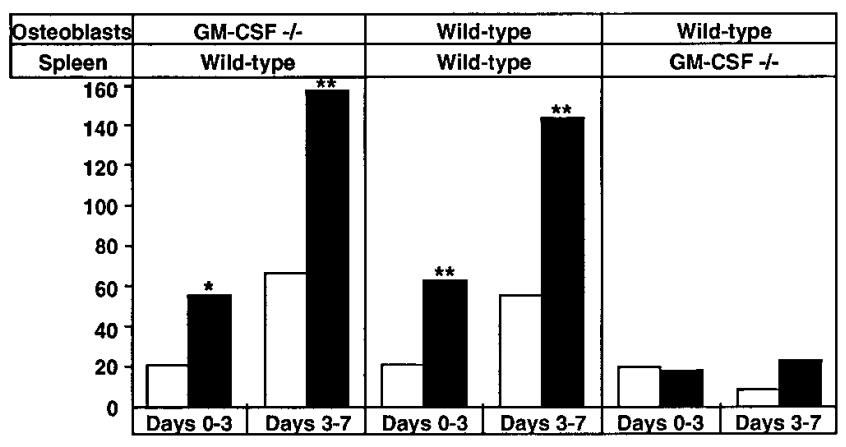

Figure 3. Murine GM-CSF ELISA. Coculture media from $1 \alpha, 25(\mathrm{OH})_{2} \mathrm{D}_{3}+\mathrm{PGE}_{2}$ as control (open bars) and media from $1 \alpha, 25(\mathrm{OH})_{2} \mathrm{D}_{3}+$ PGE2 + IL-18 (10 ng/ml; filled bars), respectively. Media were aspirated at days 3 and 7 and GM-CSF levels measured in picograms per milliliter. Coculture combinations were GM-CSF -/osteoblasts with WT spleen, WT osteoblasts with GM-CSF -/spleen cells, and WT osteoblasts with WT spleen cells, respectively. Statistical analysis was performed using Dunnett two-tailed test. $* P<0.05,{ }^{* *} P<0.01$ compared with the control.

level of $55 \mathrm{pg} / \mathrm{ml}$ at day 3 and $150 \mathrm{pg} / \mathrm{ml}$ at day 7 as compared with the control $\left[1 \alpha, 25(\mathrm{OH})_{2} \mathrm{D}_{3}\right.$ and $\left.\mathrm{PGE}_{2}\right]$ measurements of 20 and $65 \mathrm{pg} / \mathrm{ml}$, respectively. The levels of GM-CSF produced in response to IL-18 stimulation equate with the concentration of exogenous GM-CSF (100 pg/ml) required to inhibit OCL formation (Fig. $1 A$ ). Coculturing WT osteoblasts with WT spleen led to the production of similar quantities of GM-CSF in response to IL-18. However, when WT osteoblasts were cocultured with GM-CSF -/- spleen cells, IL-18 was unable to elevate GM-CSF levels beyond that of the control level, $<20 \mathrm{pg} / \mathrm{ml}$ (Fig. 3). These data further illustrated the importance of the spleen cell population rather than the osteoblastic cells as the target of IL-18 action as well as confirming that the production of endogenous GM-CSF occurred in response to IL-18.
IL-18 action on T cells. As T cells comprise $30-40 \%$ of the spleen cell population, we investigated the role of $\mathrm{T}$ cells in IL-18-induced inhibition of OCL formation. Using cocultures of osteoblastic cells and mature macrophages isolated from $\mathrm{M}-\mathrm{CSF}-$ induced colonies in methylcellulose culture, OCL were formed in the presence of $1 \alpha, 25(\mathrm{OH})_{2} \mathrm{D}_{3}$ and $\mathrm{PGE}_{2}$, yet IL-18 $(100 \mathrm{ng} / \mathrm{ml})$ showed no inhibitory effects (Fig. $4 A$ ). As both bone marrow and spleen contain a significant number of T lymphocytes, T cells were extracted from mouse spleen using a $\mathrm{T}$ cell recovery column. The addition of the enriched $\mathrm{T}$ cell fraction was able to restore the inhibitory action of IL-18 (25 $\mathrm{ng} / \mathrm{ml}$ ) in these cocultures (Fig. $4 \mathrm{~B}$ ). Although the T cell recovery column removed virtually all mouse B lymphocytes, the monocyte/macrophage component of the spleen population was not completely removed, thus it may contaminate the T cell-enriched eluant. A definitive conclusion as to the target cell of IL-18 could not be reached because of this potential contamination. Subsequently, both nude mice and severe combined immune deficient (SCID) mice were used in coculture experiments, yet the addition of IL-18 was still able to inhibit OCL formation, contrary to what would be expected in these predominantly $\mathrm{T}$ cell-deficient mice (data not shown). Finally we used mouse pan T Dynabeads for the depletion of total $\mathrm{T}$ cells. These beads are precoated with a rat monoclonal antibody to the Thy 1.2 membrane antigen which is predominantly expressed on peripheral $\mathrm{T}$ cells, thymocytes, and intraepithelial T lymphocytes. All the cocultures were established using GM-CSF - /- primary osteoblasts to remove any background effects of endogenous GM-CSF production. WT or GM-CSF - /- spleen cells depleted of T cells and the T cells attached to the Thy 1.2-precoated Dynabeads were used, giving rise to six different combinations: (1) GM-CSF -/- spleen with WT T cells; (2) GM-CSF -/- spleen with GM-CSF -/T cells; (3) GM-CSF -/- spleen alone; (4) WT spleen with WT T cells; (5) WT spleen with GM-CSF -/ - T cells; or (6) WT spleen alone. Combination 2 served as the control for the GM-CSF -/- coculture where IL-18 was unable to inhibit OCL formation and GM-CSF was still inhibitory (Fig. 5). Combina-
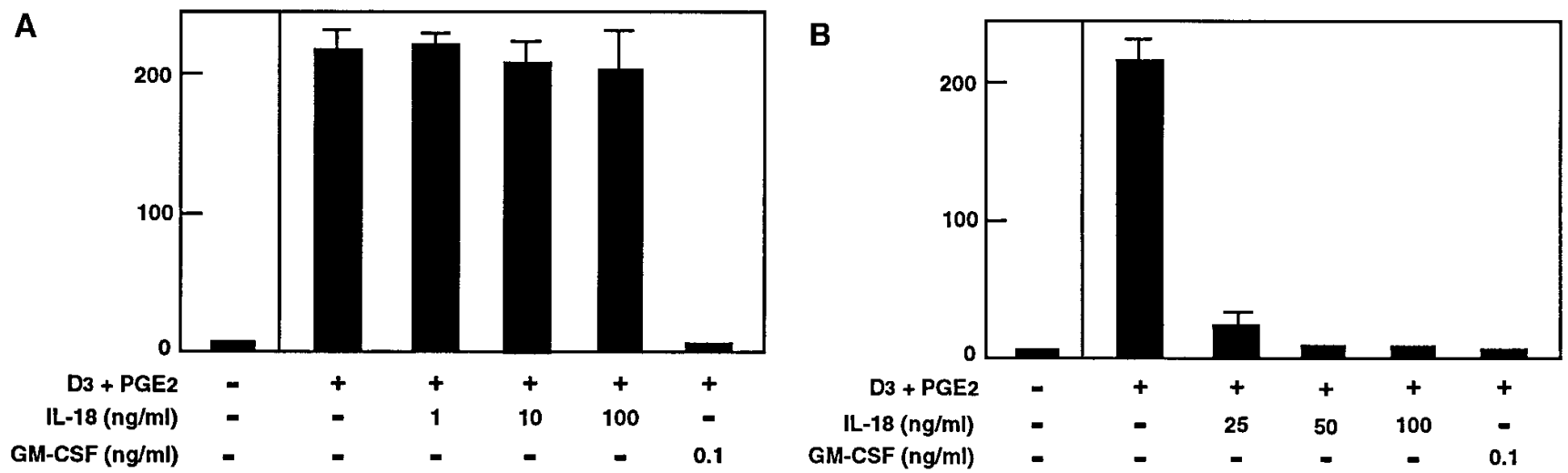

Figure 4. (A) OCL formation in cocultures of primary osteoblasts and methylcellulose-derived macrophages. Cocultures were performed in the presence of $1 \alpha, 25(\mathrm{OH})_{2} \mathrm{D}_{3}$ and $\mathrm{PGE}_{2}$ and treated with increasing doses of IL-18 $(1,10$, and $100 \mathrm{ng} / \mathrm{ml})$ or GM-CSF $(0.1 \mathrm{ng} / \mathrm{ml})$. For negative and positive controls, cocultures were performed in the absence and presence of $1 \alpha, 25(\mathrm{OH})_{2} \mathrm{D}_{3}$ and $\mathrm{PGE}_{2}$, respectively. After culture for $7 \mathrm{~d}$, TRAPpositive OCLs were counted. Each coculture was repeated three times in quadruplicate wells and expressed as the means \pm SEM. $(B)$ Effect of the addition of a T cell-enriched spleen fraction on OCL formation in cocultures of primary osteoblasts and methylcellulose-derived macrophages. Cocultures were performed in the presence of $1 \alpha, 25(\mathrm{OH})_{2} \mathrm{D}_{3}$ and $\mathrm{PGE}_{2}$ and treated with increasing doses of IL-18 (25, 50, and $100 \mathrm{ng} / \mathrm{ml})$ or GM-CSF $(0.1 \mathrm{ng} / \mathrm{ml})$. For negative and positive controls, cocultures were performed in the absence and presence of $1 \alpha, 25(\mathrm{OH})_{2} \mathrm{D}_{3}$ and $\mathrm{PGE}_{2}$, respectively. After culture for $7 \mathrm{~d}$, TRAP-positive OCLs were counted. Each coculture was repeated three times in quadruplicate wells and expressed as the means \pm SEM. 


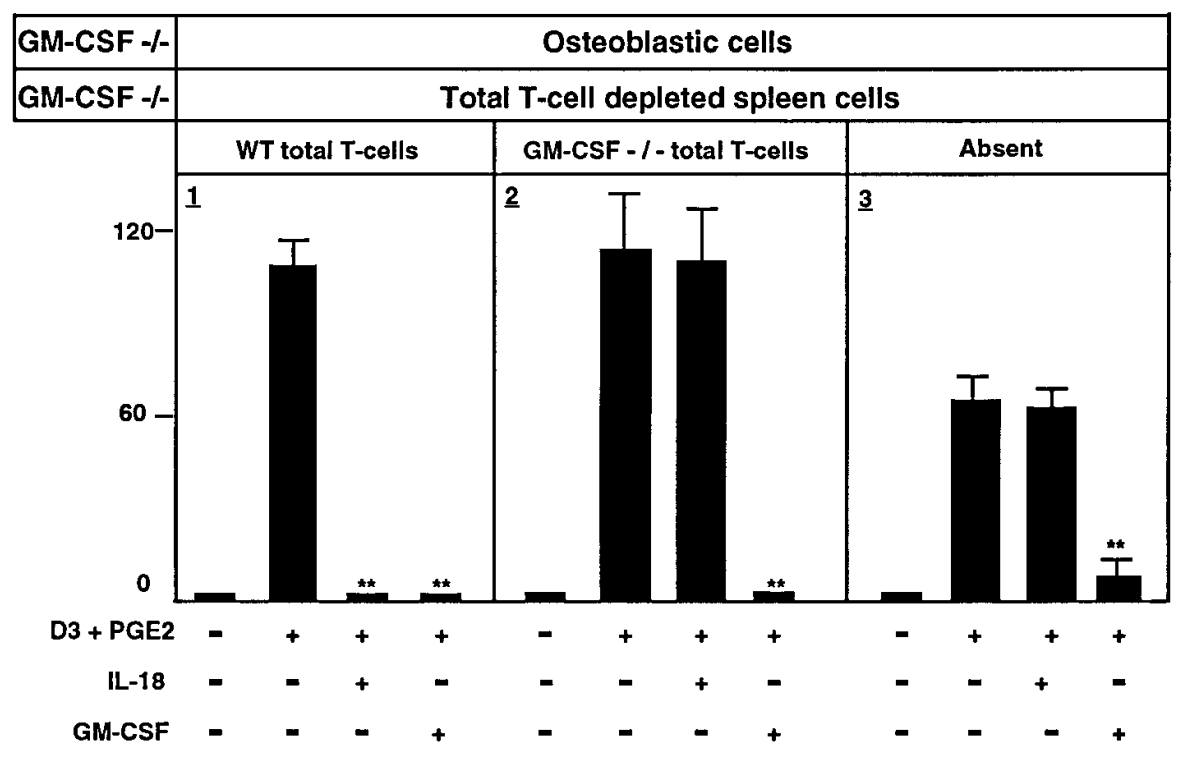

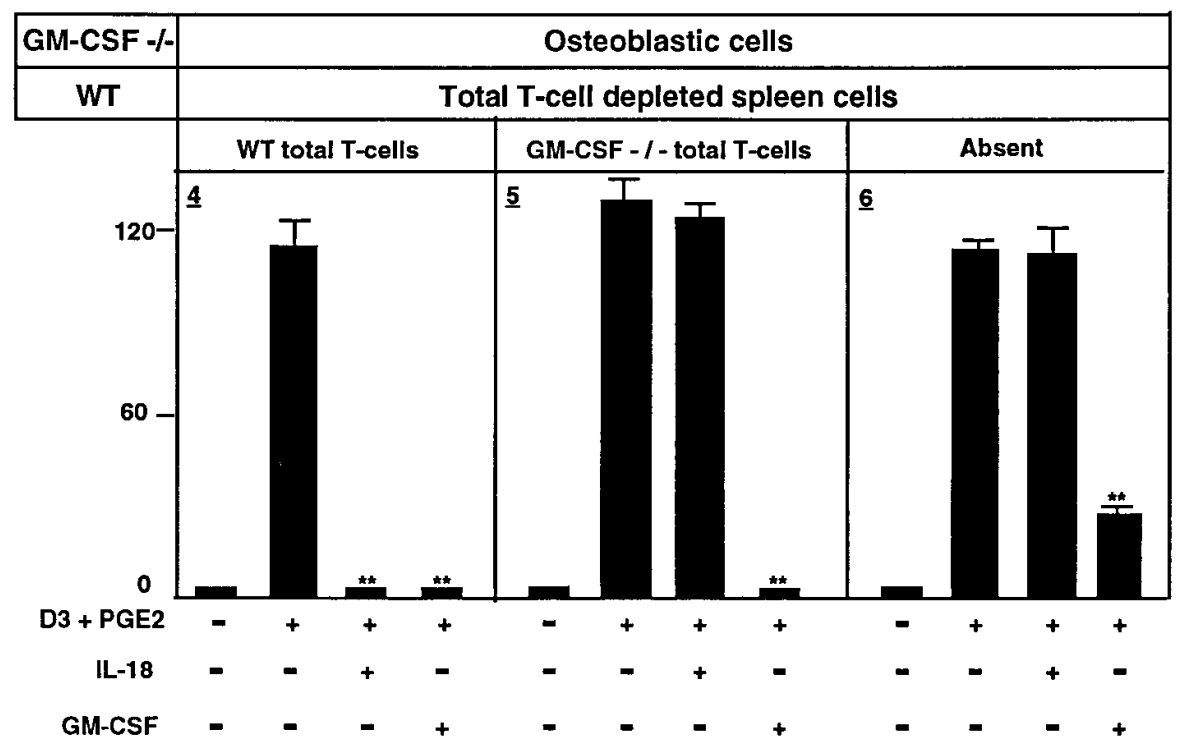

Figure 5. Effect of total T cells on OCL formation. OCL formation in cocultures of GM-CSF $-/-$ osteoblastic cells and total T cell-depleted GM-CSF - /- spleen (combinations 1-3) or total $\mathrm{T}$ cell depleted WT spleen (combinations 4-6). Total $\mathrm{T}$ cells were added to the cocultures from either WT or GM-CSF - /- mice, or remained absent. Cocultures were performed in the presence of $1 \alpha, 25(\mathrm{OH})_{2} \mathrm{D}_{3}$ and $\mathrm{PGE}_{2}$ and treated with IL-18 $(10 \mathrm{ng} / \mathrm{ml})$ or GM$\operatorname{CSF}(0.1 \mathrm{ng} / \mathrm{ml})$. For negative and positive controls, cocultures were performed in the absence and presence of $1 \alpha, 25(\mathrm{OH})_{2} \mathrm{D}_{3}$ and $\mathrm{PGE}_{2}$, respectively. After culture for 7 d, TRAP-positive OCLs were counted. Each coculture was performed four times in quadruplicate wells and expressed as the means \pm SEM. Statistical analysis was performed using Dunnett two-tailed test. ** $P<0.01$ compared with the positive control. tion 3 showed that in the complete absence of T cells, IL-18 remained ineffective, whereas GM-CSF was inhibitory (Fig. 5). The inclusion of WT T cells in an otherwise GM-CSF -/ - coculture as depicted in combination 1 led to the total inhibition of OCL formation after either IL-18 or GM-CSF treatment (Fig. 5). Further proof of the importance of $\mathrm{T}$ cells and their production of GM-CSF was gained from the remaining three combinations. Combination 4 controlled for the coculture of WT spleen with GM-CSF -/- osteoblasts and confirmed the inhibitory action of IL-18 and GM-CSF in the presence of WT T cells (Fig. 5). Combination 6 revealed that cocultures lacking WT T cells were unresponsive to IL-18 yet GM-CSF still inhibited OCL formation (Fig. 5). Lastly, the addition of GM-CSF - / - T cells with WT spleen cells (combination 5) rendered IL-18 ineffective, whereas GM-CSF remained capable of inhibiting OCL formation (Fig. 5). Furthermore, in T cell-depleted GM-CSF - /- cocultures, the addition of GM-
CSF R -/ - total T cells restored the action of IL-18 (data not shown). These data demonstrated conclusively that $\mathrm{T}$ cells were an intermediate in the IL-18 pathway of OCL inhibition, moreover, the ability of T cells to produce GM-CSF was crucial for the inhibitory effects of IL-18.

T cell subsets: $C D 4^{+}$. T cells can be divided into distinct groups on the basis of their cell surface markers and the cytokines produced by these cells. The two major types of mature $\mathrm{T}$ cells are those carrying either the CD4 or CD8 membrane antigen. $\mathrm{CD}^{+}$cells differentiate into functionally distinct subsets, Th1 or Th2. IL-18 reportedly enhances T cell proliferation and leads to Th1 cytokine production including IL-2, IFN- $\gamma$, and GM-CSF (11). To investigate the role of CD $4^{+}$ $\mathrm{T}$ cells in the coculture system, cocultures using the same conditions as for the total $\mathrm{T}$ cell depletion/repletion were undertaken using mouse CD4 Dynabeads to alter the $\mathrm{CD}^{+}{ }^{+} \mathrm{T}$ cell population. These magnetic beads are precoated with a rat 
monoclonal antibody to the L3T4 membrane antigen which is expressed on thymocytes and the $\mathrm{T}$ helper subset of mature $\mathrm{T}$ cells. The six coculture combinations were assessed with osteoblasts derived from GM-CSF -/- mice: (1) GM-CSF -/spleen with WT CD4 ${ }^{+}$T cells; (2) GM-CSF -/- spleen with GM-CSF $-/-\mathrm{CD}^{+}{ }^{+} \mathrm{T}$ cells; (3) GM-CSF $-/-$ spleen minus the $\mathrm{CD}^{+}$population; (4) WT spleen with WT CD4 ${ }^{+} \mathrm{T}$ cells; (5) WT spleen with GM-CSF $-/-\mathrm{CD}^{+} \mathrm{T}$ cells; or (6) WT spleen minus the $\mathrm{CD}^{+}$population. Combination 2 was the control for the GM-CSF -/- coculture where IL-18 was unable to inhibit OCL formation and GM-CSF was still inhibitory in agreement with Fig. $1 B$ (Fig. 6). Combination 3 showed that in the complete absence of $\mathrm{CD}^{+} \mathrm{T}$ cells, IL-18 remained ineffective (not significantly different from the controls in combination 2), whereas GM-CSF was inhibitory (Fig. 6). On the other hand, WT CD4 ${ }^{+} \mathrm{T}$ cells in an otherwise GM-
CSF $-/-$ coculture as depicted in combination 1 led to the inhibition of OCL formation with either IL-18 or GM-CSF (Fig. $6)$. These results were identical to those obtained after total $\mathrm{T}$ cell depletion in a GM-CSF -/- background (Fig. 5). Combination 4 controlled for the coculture of WT spleen with GMCSF $-1-$ osteoblasts and confirmed the inhibitory action of IL-18 and GM-CSF in the presence of WT CD4 ${ }^{+} \mathrm{T}$ cells (Fig. 6). However, the substitution of GM-CSF $-/-\mathrm{CD}^{+} \mathrm{T}$ cells for the wild type shown in combination 5 did not hinder the activity of IL-18, likewise in the absence of $\mathrm{CD}^{+} \mathrm{T}$ cells shown in combination 6 the OCL inhibition by IL-18 was not impaired (Fig. 6).

T cell subsets: $\mathrm{CD}^{+}$. The role of $\mathrm{CD}^{+} \mathrm{T}$ cells in the coculture system was also examined using the same conditions as for the total or $\mathrm{CD}^{+} \mathrm{T}$ cell depletion/repletion. Mouse CD8 Dynabeads are precoated with a rat monoclonal antibody to

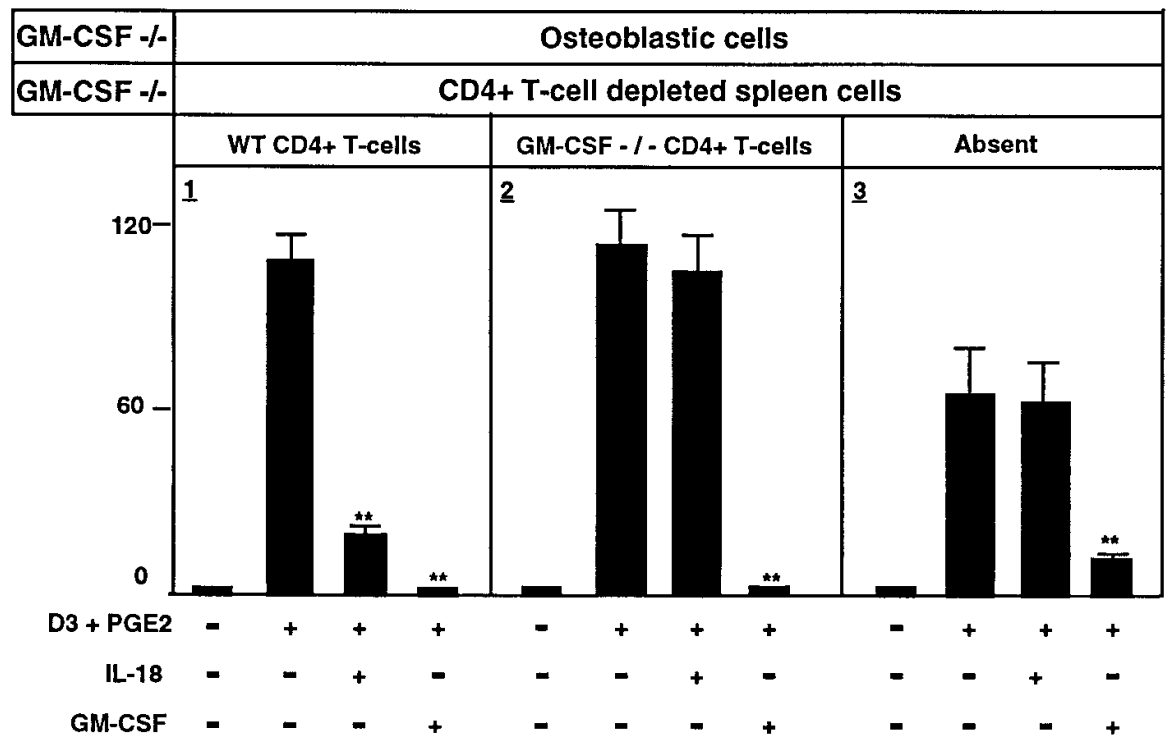

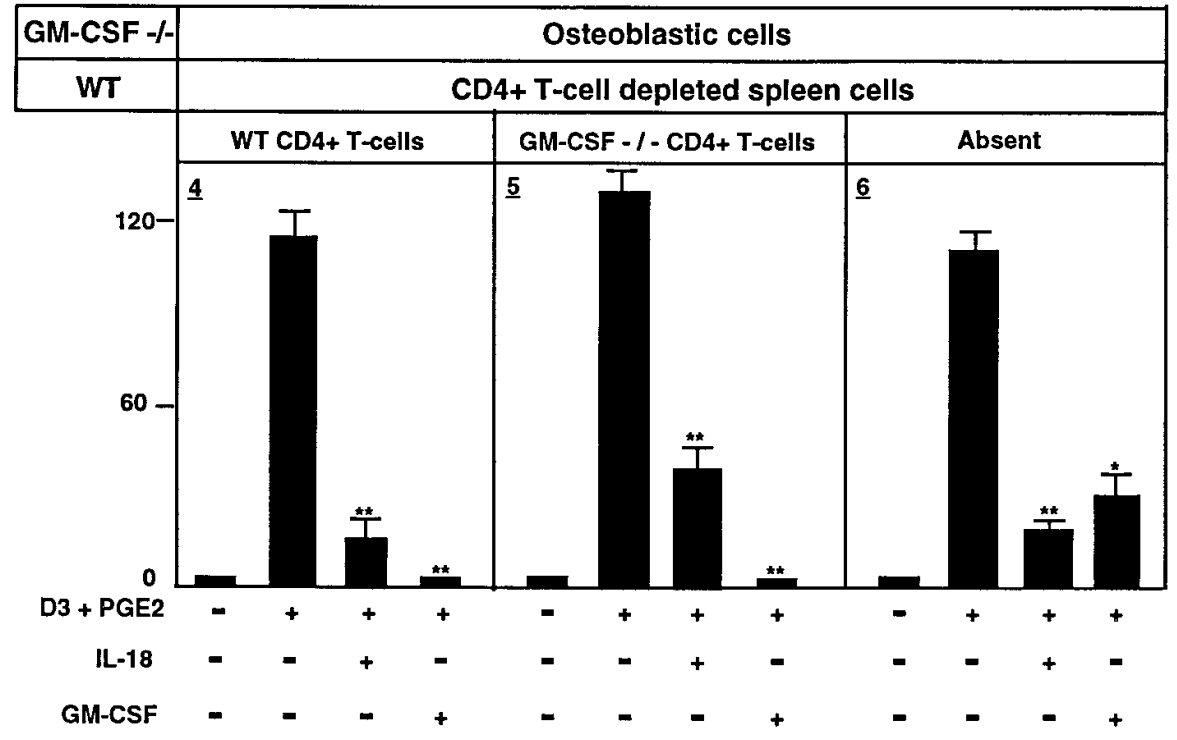

Figure 6. Effect of $\mathrm{CD}^{+}{ }^{+} \mathrm{T}$ cells on $\mathrm{OCL}$ formation and actions of IL-18 and GM-CSF. OCL formation in cocultures of GM-CSF $-/-$ osteoblastic cells and CD4 ${ }^{+}$ T cell-depleted GM-CSF $-/$ - spleen (combinations 1-3) or $\mathrm{CD} 4{ }^{+} \mathrm{T}$ celldepleted WT spleen (combinations 4-6). $\mathrm{CD}^{+} \mathrm{T}$ cells were added to the cocultures from either WT or GM-CSF - /- mice, or remained absent. Cocultures were performed in the presence of $1 \alpha, 25(\mathrm{OH})_{2} \mathrm{D}_{3}$ and $\mathrm{PGE}_{2}$ and treated with IL-18 $(10 \mathrm{ng} / \mathrm{ml})$ or GM-CSF $(0.1 \mathrm{ng} / \mathrm{ml})$. For negative and positive controls, cocultures were performed in the absence and presence of $1 \alpha, 25(\mathrm{OH})_{2} \mathrm{D}_{3}$ and $\mathrm{PGE}_{2}$, respectively. After culture for $7 \mathrm{~d}$, TRAP-positive OCLs were counted. Each coculture was performed five times in quadruplicate wells and expressed as the means \pm SEM. Statistical analysis was performed using Dunnett two-tailed test. $* P<0.05$, $* * P<0.01 \mathrm{com}$ pared with the positive control. 

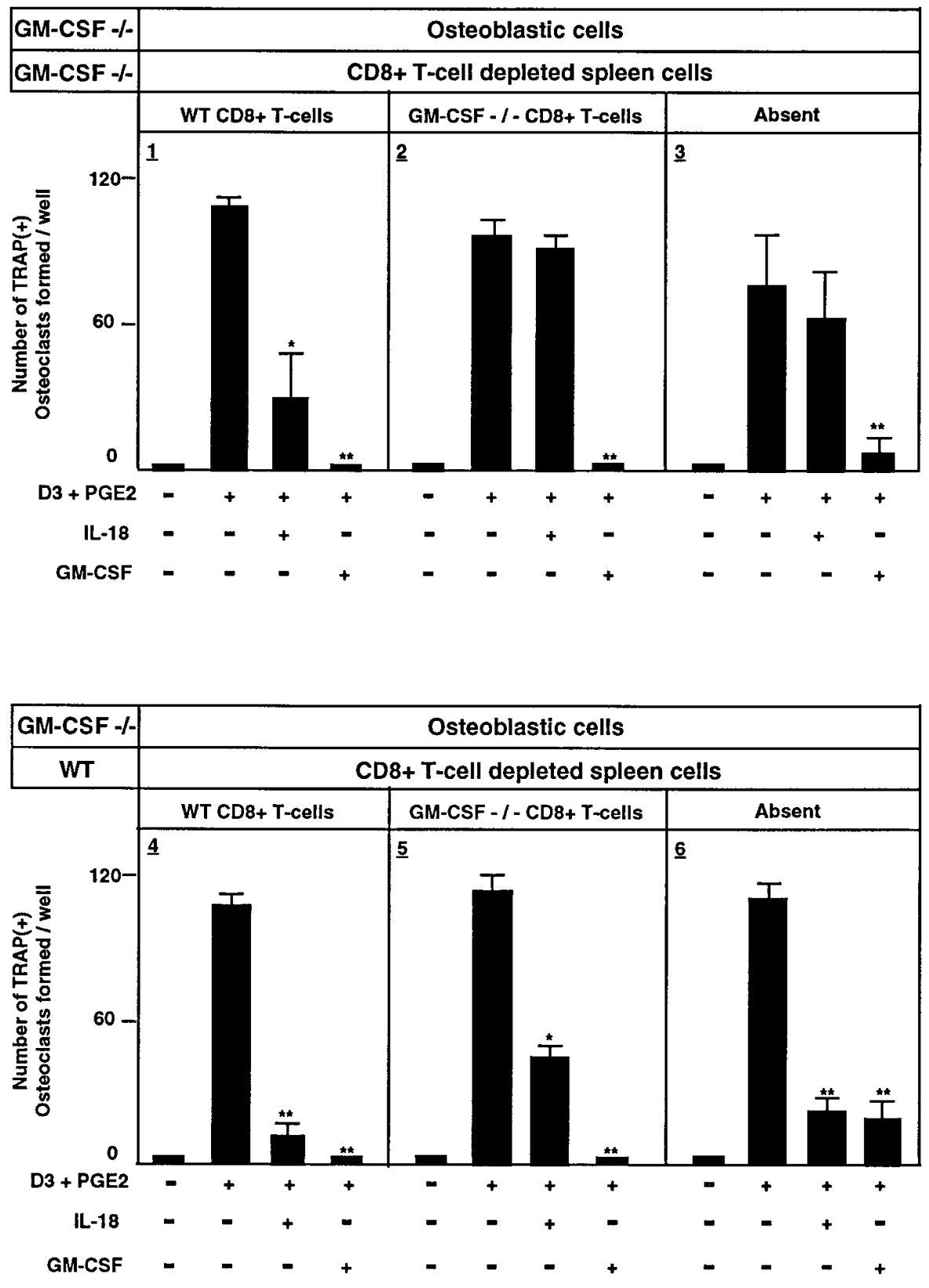

Figure 7. Effect of $\mathrm{CD}^{+} \mathrm{T}$ cells on $\mathrm{OCL}$ formation and actions of IL-18 and GM-CSF. OCL formation in cocultures of GM-CSF $-/-$ osteoblastic cells and $\mathrm{CD}^{+}$ T cell-depleted GM-CSF $-1-$ spleen (combinations 1-3) or $\mathrm{CD}^{+} \mathrm{T}$ celldepleted WT spleen (combinations 4-6). $\mathrm{CD}^{+} \mathrm{T}$ cells were added to the cocultures from either WT or GM-CSF - /- mice, or remained absent. Cocultures were performed in the presence of $1 \alpha, 25(\mathrm{OH})_{2} \mathrm{D}_{3}$ and $\mathrm{PGE}_{2}$ and treated with IL-18 (10 ng/ $\mathrm{ml})$ or GM-CSF $(0.1 \mathrm{ng} / \mathrm{ml})$. For negative and positive controls, cocultures were performed in the absence and presence of $1 \alpha, 25(\mathrm{OH})_{2} \mathrm{D}_{3}$ and $\mathrm{PGE}_{2}$, respectively. After culture for $7 \mathrm{~d}$, TRAP-positive OCLs were counted. Each coculture was performed four times in quadruplicate wells and expressed as the means \pm SEM. Statistical analysis was performed using Dunnett two-tailed test. $* P<0.05$, ** $P<0.01 \mathrm{com}$ pared with the positive control.

the Lyt2 membrane antigen which is expressed on most thymocytes and the $\mathrm{T}$ cytotoxic/suppressor subpopulation. The six coculture combinations using the $\mathrm{CD}^{+}$population were undertaken as outlined in the previous $\mathrm{T}$ cell experiments. The addition of WT $\mathrm{CD}^{+} \mathrm{T}$ cells to GM-CSF $-/-$ spleen resulted in the restoration of IL-18 activity (combination 1). However, the addition of GM-CSF $-/-\mathrm{CD}^{+} \mathrm{T}$ cells to WT spleen did not prevent the OCL inhibitory action of IL-18 (combination 5; Fig. 7). These results were similar to those obtained with the $\mathrm{CD} 4^{+}$depletion/repletion experiments and suggest that either $T$ cell subset is able to elicit the effects of IL-18 in this in vitro OCL formation model.

\section{Discussion}

We have reported previously that IL-18 can inhibit OCL formation in murine cocultures in a manner similar to GM-CSF and that this inhibition could be reversed by neutralizing antibodies to GM-CSF (13). Confirmation that GM-CSF functions as a mediator of the inhibitory action of IL-18 upon OCL formation has been obtained in this report by using cocultures with both GM-CSF-deficient mice and GM-CSF/IL-3/IL-5 $\beta$ chain receptor-deficient mice in conjunction with WT mice. Interestingly, neither of the knockout mice exhibits obvious skeletal abnormalities although both develop lung abnormalities similar to the human disorder alveolar proteinosis $(14,15)$.

Cocultures in a GM-CSF-deficient background or cocultures of cells lacking the ability to form high-affinity receptors for GM-CSF render IL-18 unable to inhibit OCL formation. Exogenous GM-CSF dose-dependently inhibited OCL formation in both WT and GM-CSF $-/-$ cocultures, yet showed no effect in GM-CSF $\mathrm{R}-/-$ cocultures, thus providing clear evidence that IL-18 inhibits OCL formation via GM-CSF production. This is surprising since IL-18 can stimulate IFN- $\gamma$ pro- 
duction, a known inhibitor of OCL formation (9-12). Consequently, this would argue that IL-18 does not induce IFN- $\gamma$ production to inhibitory levels.

The spleen cell population was highlighted as the target of IL-18 action, since coculture of either GM-CSF - /- or GMCSF R -/- spleen cells with WT osteoblastic cells resulted in the loss of IL-18 inhibitory actions on OCL formation. In the reciprocal situation, IL-18 completely abolished OCL formation. Additionally, WT spleen cells were required for IL-18-induced GM-CSF production as determined by ELISA. Since IL-18 potently induced IFN- $\gamma$ and GM-CSF production by $\mathrm{T}$ cells (11) and T cells comprise $30-40 \%$ of the spleen cell population, we investigated their role in OCL inhibition due to IL-18.

Total T cells were removed from both WT and GM-CSF $-/-$ spleen cells and the effect of $\mathrm{T}$ cell repletion in a variety of combinations was assessed. The complete absence of $\mathrm{T}$ cells abolished the action of IL-18 on OCL formation, whereas GM-CSF was still active. The addition of WT T cells to an otherwise GM-CSF -/- background permitted the inhibition of OCL formation by IL-18. Likewise, the addition of GM-CSF $-/-\mathrm{T}$ cells to WT spleen cells removed such inhibition. Hence the cellular target of IL-18 in this coculture system was identified as the $T$ cell population, whereas GM-CSF acts directly on the OCL precursors (Fig. 8).

In this scheme (Fig. 8), IL-18 is produced by stromal cells (13) or other cells of the bone microenvironment, which acts on T cells, via an as yet unidentified receptor, to increase GMCSF production, which ultimately inhibits osteoclastogenesis. IL-18 reportedly activates NF- $\mathrm{KB}$ production in murine $\mathrm{T}$ helper type 1 cells (19) and thus we would postulate that this transcription factor could also be responsible for elevating GMCSF production by the $\mathrm{T}$ cells.

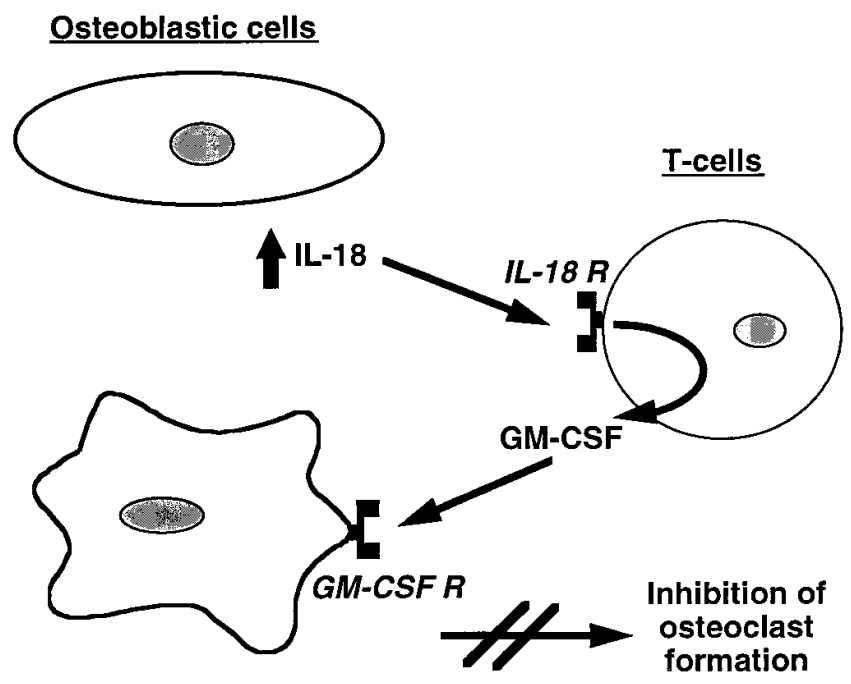

Osteoclast precursors

(monocyte-macrophage lineage)

Figure 8. Proposed mechanism of IL-18 and GM-CSF inhibition of OCL formation. In this scheme, IL-18 is produced by cells in the bone microenvironment and binds to its receptor on T cells to activate GM-CSF production. Secreted GM-CSF then binds to the GMCSF R on osteoclastic precursors to inhibit proliferation/differentiation.
This proposal is consistent with our results obtained with neutralizing antibodies to GM-CSF (13) and the observed actions of IL-18 and GM-CSF in GM-CSF - /- and GMCSF $\mathrm{R}-/-$ mice. The nature of the subset(s) of $\mathrm{T}$ cells involved was investigated by the individual depletion of $\mathrm{CD}^{+}$or $\mathrm{CD}^{+} \mathrm{T}$ cells. In cocultures with GM-CSF $-/-$ spleen cells and osteoblastic cells, repletion with either $\mathrm{WT} \mathrm{CD} 4^{+}$or $\mathrm{CD} 8^{+}$ $\mathrm{T}$ cells allowed IL-18 to inhibit OCL formation. IL-18 remained effective when either $\mathrm{CD}^{+}$or $\mathrm{CD}^{+} \mathrm{T}$ cells derived from the GM-CSF $-1-$ mice were introduced to WT spleen. Furthermore, WT spleen cells depleted of either the $\mathrm{CD}^{+}$or the $\mathrm{CD}^{+}$population continued to show an inhibition of OCL formation in response to IL-18 treatment. These results, together with the total $\mathrm{T}$ cell depletion data, indicated that either $\mathrm{CD}^{+}{ }^{+}$or $\mathrm{CD}^{+} \mathrm{T}$ cell subsets were able to induce this inhibitory action. In other systems, IL-18 action is not restricted to only one cell type; it has been shown to act directly on Th1 cells (19), on B cells (12), and can enhance natural killer cell cytotoxicity (9).

The potential involvement of $\mathrm{T}$ cells in osteoclastogenesis has been observed by several investigators. Administration of $\mathrm{T}$ cell immunosuppressants, such as cyclosporin A, manifested an increase in bone resorption and high turnover osteopenia in rats (20). However, studies of bone metabolism in T lymphocyte-deficient and -replete strains of rat tend to indicate that the $\mathrm{T}$ cell deficiency was not necessarily associated with high turnover osteopenia. T cell-deficient rats, rnu/rnu homozygotes, do not display abnormalities in bone metabolism, however they are resistant to cyclosporin A-induced osteopenia (21). This situation may explain our finding that IL-18 was still capable of inhibiting OCL formation in both nude and SCID mice. Conversely, a positive correlation exists in HIV patients where the reduction of $\mathrm{CD}^{+} \mathrm{T}$ cells occurs with a notable decrease in bone formation and turnover (22), and children with histiocytosis- $\mathrm{X}$ also show an imbalance in their $\mathrm{CD}^{+} / \mathrm{CD} 8^{+}$ ratio due to a deficiency of $\mathrm{CD}^{+} \mathrm{T}$ cells which manifests as bone loss $(23,24)$. John et al. (8) have also provided evidence that $\mathrm{CD} 8^{+} \mathrm{T}$ lymphocytes may be involved in OCL differentiation.

The requirement for $\mathrm{T}$ cells to elicit the inhibitory actions of IL-18 on OCL formation supports the proposal that IL-18 acts as a local inhibitory agent (13). This proposition is also supported in vivo with the GM-CSF -/-, GM-CSF R -/-, and IL-1 $\beta$ converting enzyme-deficient mice (25) all lacking major skeletal abnormalities despite the inability to respond to IL-18, indicating that the IL-18/GM-CSF pathway is not central to OCL inhibition but may constitute a newly recognized inhibitory pathway able to be compensated for by other mechanisms.

\section{Acknowledgments}

This work was supported by a Program Grant from the NHMRC, Australia and Aza Research Pty. Ltd., Australia (T.J. Martin and M.T. Gillespie) and grant-in-aid 09671905 from the Ministry of Science, Education and Culture of Japan (N. Udagawa). M.T. Gillespie is a Research Fellow of the NHMRC, Australia.

\section{References}

1. Suda, T., N. Takahashi, and T.J. Martin. 1995. Modulation of osteoclast differentiation: update. In Endocrine Rev. Monographs. Vol. 4. D.D. Bikle and A. Negrovilar, editors. Endocrine Society, Bethesda, MD. 266-270. 
2. Martin, T.J., and K.W. Ng. 1994. Mechanisms by which cells of the osteoblast lineage control osteoclast formation and activity. J. Cell. Biochem. 56:357-366.

3. Takahashi, N., T. Akatsu, N. Udagawa, T. Sasaki, A. Yamaguchi, J.M. Moseley, T.J. Martin, and T. Suda. 1988. Osteoblastic cells are involved in osteoclast formation. Endocrinology. 123:2600-2602.

4. Rosen, C.J., K. Usiskin, M. Owens, C.O. Barlascini, M. Belsky, and R.A. Adler. 1990. T lymphocyte surface antigen markers in osteoporosis. J. Bone Miner. Res. 5:851-855.

5. Abrahamsen, B., K. Bendtzen, and H. Beck-Nielsen. 1997. Cytokines and T-lymphocyte subsets in healthy post-menopausal women: estrogen retards bone loss without affecting the release of IL-1 or IL-1ra. Bone. 20:251-258.

6. Hustmyer, F.G., E. Walker, X.-P. Yu, G. Girasole, Y. Sakagami, M. Peacock, and S.C. Manolagas. 1993. Cytokine production and surface antigen expression by peripheral blood mononuclear cells in postmenopausal osteoporosis. J. Bone Miner. Res. 8:51-59.

7. Buchinsky, F.J., Y. Ma, G.N. Mann, B. Rucinski, H.P. Bryer, D.F. Romero, W.S.S. Jee, and S. Epstein. 1996. T lymphocytes play a crucial role in the development of cyclosporin A-induced osteopenia. Endocrinology. 137: $2278-2285$.

8. John, V., J.M. Hock, L.L. Short, A.L. Glasebrook, and R.J. Sells Galvin. 1996. A role for CD8+ T lymphocytes in osteoclast differentiation in vitro. Endocrinology. 137:2457-2463.

9. Okamura, H., H. Tsutsui, T. Komatsu, M. Yutsudo, A. Hakura, T. Tanimoto, K. Torigoe, T. Okura, Y. Nukada, K. Hattori, et al. 1995. Cloning of a new cytokine that induces IFN- $\gamma$ production by T cells. Nature. 378:88-91.

10. Ushio, S., M. Namba, T. Okura, K. Hattori, Y. Nukada, K. Akita, F. Tanabe, K. Konishi, M. Micallef, M. Fujii, et al. 1996 Cloning of the cDNA for human IFN- $\gamma$-inducing factor, expression in Escherichia coli, and studies on the biologic activities of the protein. J. Immunol. 156:4274-4279.

11. Micallef, M.J., O. Takashi, K. Kohno, F. Tanabe, S. Ushio, M. Namba, T. Tanimoto, K. Torigoe, M. Fujii, M. Ikeda, et al. 1996. Interferon- $\gamma$-inducing factor enhances $\mathrm{T}$ helper 1 cytokine production by stimulated human $\mathrm{T}$ cells: synergism with interleukin-12 for interferon- $\gamma$ production. Eur. J. Immunol. 26: $1647-1651$.

12. Yoshimoto, T., H. Okamura, Y.-I. Tagawa, Y. Iwakura, and K. Nakanishi. 1997. Interleukin 18 together with interleukin 12 inhibits IgE production by induction of interferon- $\gamma$ production from activated B cells. Proc. Natl. Acad. Sci. USA. 94:3948-3953.

13. Udagawa, N., N.J. Horwood, J. Elliott, A. Mackay, J. Owens, H. Okamura, M. Kurimoto, T.J. Chambers, T.J. Martin, and M.T. Gillespie. 1997. Interleukin 18 (interferon- $\boldsymbol{\gamma}$-inducing factor) is produced by osteoblasts and acts via granulocyte-macrophage colony-stimulating factor and not via interferon- $\gamma$ to inhibit osteoclast formation. J. Exp. Med. 185:1005-1012.

14. Stanley, E., G.J. Lieschke, D. Grail, D. Metcalf, G. Hodgson, J.A.M. Gall, D.W. Maher, J. Cebon, V. Sinickas, and A.R. Dunn. 1994. Granulocyte/ macrophage colony-stimulating factor-deficient mice show no major perturbation of hematopoiesis but develop a characteristic pulmonary pathology. Proc. Natl. Acad. Sci. USA. 91:5592-5596.

15. Robb, L., C.C. Drinkwater, D. Metcalf, R. Li, F. Kontgen, N.A. Nicola, and C.G. Begley. 1995. Hematopoietic and lung abnormalities in mice with a null mutation of the common $\beta$ subunit of the receptors for granulocyte-macrophage colony-stimulating factor and interleukins 3 and 5. Proc. Natl. Acad. Sci. USA. 92:9565-9569.

16. Udagawa, N., N. Takahashi, T. Akatsu, T. Sasaki, A. Yamaguchi, H. Kodama, T.J. Martin, and T. Suda. 1989. The bone marrow-derived stromal cell lines MC3T3-G2/PA6 and ST2 support osteoclast-like cell differentiation in cocultures with mouse spleen cells. Endocrinology. 125:1805-1813.

17. Chambers, T.J., P.A. Revell, K. Fuller, and N.A. Athanasou. 1984. Resorption of bone by isolated rabbit osteoclasts. J. Cell Sci. 66:383-399.

18. Metcalf, D., and N.A. Nicola. 1992. The clonal proliferation of normal mouse hematopoietic cells: enhancement and suppression by colony-stimulating factor combinations. Blood. 79:2861-2866.

19. Matsumoto, S., K. Tsuji-Takayama, Y. Aizawa, K. Koide, M. Takeuchi, T. Ohta, and M. Kurimoto. 1997. Interleukin-18 activates NF-кB in murine T helper type 1 cells. Biochem. Biophys. Res. Commun. 234:454-457.

20. Movsowitz, C., S. Epstein, M. Fallon, M. Ismail, and F. Thomas. 1988. Cyclosporin A in vivo produces severe osteopenia in the rat: effect of dose and duration of administration. Endocrinology. 123:2571-2577.

21. Buchinsky, F.J., Y. Ma, G.N. Mann, B. Rucinski, H.P. Bryer, B.V. Paynton, W.S.S. Jee, G.N. Hendy, and S. Epstein. 1995. Bone mineral metabolism in T lymphocyte-deficient and -replete strains of rat. J. Bone. Miner. Res. 10:15561565.

22. Serrano, S., M.L. Marinoso, J.C. Soriano, J. Rubies-Prat, J. Aubia, J. Coll, J. Bosch, L. Del Rio, J. Vila, A. Goday, and M. Nacher. 1995. Bone remodelling in human immunodeficiency virus-1-infected patients. A histomorphometric study. Bone. 16:185-191.

23. Consolini, R., P. Cini, B. Cei, and E. Bottone. 1987. Thymic dysfunction in histiocytosis-X. Am. J. Ped. Hematol. Oncol. 9:146-148.

24. Cline, M. 1994. Histiocytes and histiocytosis. Blood. 84:2840-2863.

25. Li, P., H. Allen, S. Banerjee, and T. Seshadri. 1997. Characterization of mice deficient in interleukin-1 $\beta$ converting enzyme. J. Cell. Biochem. 64:27-32. 